\title{
The validity and reliability of Kogan's attitude towards old people scale in the Turkish society
}

\author{
Dilek Kiliç, , Derya Adibelli
}

Department of Nursing, Health Sciences Faculty, Ataturk University, Erzurum, Turkey;

${ }^{\#}$ Corresponding Author: dkilic25@mynet.com

Received July 28 ${ }^{\text {th }}, 2011$; revised August $9^{\text {th }}, 2011$; accepted August 25 $5^{\text {th }}, 2011$.

\begin{abstract}
This study was conducted methodologically in order to determine the validity and reliability of Kogan's Attitude towards Old People Scale after being adapted to the Turkish Society. 145 female students, attending the $4^{\text {th }}$ and $5^{\text {th }}$ year of the faculty of Medical Sciences at Atatürk University, and 118 nurses, working at Ataturk University Aziziye-Yakutiye Research Hospitals, were included in the study. The sample group was chosen from the population using a non-probability convenience sampling method. A form containing demographic characteristics of nurses and nursing students, and the Turkish version of Kogan's Attitude towards Old People Scale were used to gather the required data. Data was analysed using the $t$-test, Cronbach's alpha coefficient, correlation, and factor analyses. In the study, Cronbach's Alpha Reliability Coefficient for Kogan's Attitude towards Old People Scale was $\mathbf{0 . 8 1}$, and the scale comprised of one factor. The attitude of working nurses towards old people was more positive in comparison to the attitude of student nurses. After analysis, the scale was deemed highly valid and reliable, and suitable to be used for Turkish society. The scale may be used in studies to evaluative attitude toward old people and quality of the care offered to older people.
\end{abstract}

Keywords: Older People; Attitude; Validity; Reliability; Nursing

\section{INTRODUCTION}

In Turkey, just like the rest of the world, the average

*This study was presented as a poster announcement at the Turkish Geriatrics 2010 National Elderly Health Congress, held between the $1^{\text {st }}$ and $4^{\text {th }}$ April 2010. life expectancy has increased with the increase in the level of welfare, and the rate of older people has increased within the general population. In 2010, the world population was about 6.9 billion; $27 \%$ of the population was 15 and under, $8 \%$ was 65 and over [1]. In 2010, the population in Turkey was 73.6 million; the expectation is that this population will reach 85 million in 2025 , and 94.7 million in 2050 [1]. While the population growth rate has decreased in young age groups in recent years, the population of older age groups have increased faster than the average in Turkey, and the elderly population has reached 7\% [2,3]. This indicates that nearly 5 million of the population is 65 or over. In Turkey, at birth, the life expectancy for women is 74 years, and the life expectancy for men is 69 years; the average life expectancy is 72 years [1]. The attitude towards older people differs from the attitude towards other patients because older people generally suffer from more than one illness, elderly individuals require more professional or institutional care, and with age they become dependent on others in order to carry out daily life activities as a result of these demographic changes [4].

As well as the occupational experience of care-givers, their knowledge and skills, the properties of the care environment, and the characteristics of the older people, the attitude towards older people also affect the quality of the care offered to older people [5-7]. In all communities, the attitudes towards older people are generally positive, adverse, and mixed; however, the attitude tends to be adverse. The attitude of health workers towards older people usually encompasses all three. These attitudes are affected by the individual's past life, family and beliefs, cultural values, education level, and motivation [7]. While some societies consider older people as incapable and worthless, as for traditional societies they respect their elders, and try to benefit from their wisdom, and the experience and knowledge they have accumulated over the years. While in Turkish culture respecting elders, listening to elders, and taking care of elders is a traditional and fixed expectation, nowadays, the respect 
and status of elderly within society has started to change [8]. A study conducted to assess the attitude of nurses towards older people indicated that older nurses and bachelor graduate nurses had a more positive attitude towards older people [9]. Lookinland, Lavender, and Linton determined that, in general, American and African nurses had a positive attitude towards older people, and that in comparison to retired nurses, working nurses and nurses doing a masters degree had a more positive attitude towards older people [10]. A similar study conducted to assess the attitude of working nurses towards older people indicated that in comparison to polyclinic nurses, clinic nurses had a more positive attitude towards older people [11]. Adequate knowledge is not available regarding the attitude of care-giving nurses and student nurses towards older people in Turkey.

The purpose of this study is to investigate the adaptation, validity, and reliability of Kogan's attitude towards old people scale in the Turkish society.

\section{METHODS}

\subsection{Design}

This study, aimed to determine the adaptation, validity, and reliability of the Turkish version of Kogan's Attitude towards Old People Scale, was conducted methodologically between September-December 2009 at Erzurum City Centre.

\subsection{Participants}

The study population was 263 individuals; 145 female students, attending the $3^{\text {rd }}$ and $4^{\text {th }}$ year (2008-2009 school year) of health sciences faculty at a university, and 118 nurses, working at a university hospital. In the study, the two groups were formed to assess the impact of the working environment and experience on attitude. The sample group was chosen from the population using a non-probability convenience sampling method.

\subsection{Data Collection and Procedure}

A form containing introductory characteristics of nurses and nursing students, and the Turkish version of Kogan's Attitude towards Old People Scale were used to gather the required data.

1) The form containing introductory characteristics: This form contains information about the age, class, marital status, and years of experience for nurses and nursing students.

2) Kogan's Attitude towards Old People Scale: The scale was developed by Kogan in 1961. It was established to measure the attitudes of individuals towards older people. It does not contain medical terminology; it has a social context, and is a 6-point likert-type scale [12]. As well as being used for heath workers, it is also used to determine the attitudes of society. The scale comprises of 34 items; it contains 17 positive and 17 negative statements. Odd numbered items contain a negative statement, while even numbered items contain a positive statement. In accordance with the structure of the scale, negative statements are marked as 654321 , from right to left, while positive statements are marked as 123456 , from left to right. The scores for every item are added together to give a total score; 34 is the lowest score, and 204 is the highest score obtained from the scale. A high score obtained from the scale indicates a positive attitude towards older people.

The validity and reliability of the tools used to gather data was assessed in accordance with the views of experts on the subject, and the rules stated in relevant sources [13-20]. After explaining the purpose of the study, data was gathered using a questionnaire containing the introductory characteristics form and the Turkish Kogan's Attitude towards Old People Scale form.

\subsection{Data Analysis}

Data was assessed using the $t$-test, correlation analysis, Cronbach's Alpha Coefficient, and factor analysis with SPSS (Statistical Package for Social Science) 11.0 software.

\section{RESULTS}

\subsection{Participants Demographics}

$55.1 \%$ of participants were nursing students, and $44.9 \%$ were nurses. The average age of nursing students was $20.17 \pm 1.40$, and the average age of nurses was $27.36 \pm$ 4.54 (Table 1).

\subsection{Findings Relating to the Language Validity of Kogan's Attitude towards Old People Scale}

Two different methods were used to determine the language validity of the Turkish Kogan's Attitude towards Old People Scale, having been translated from English by language experts.

1) Once the scale was translated into Turkish it was then translated back into English by an English language expert. No discrepancies were detected in conclusion of the examination conducted after the re-translation.

2) The correlation between the total scores of the Turkish and English scales was calculated. The correlation of 0.63 was determined as significant at a significance level of $p<0.05$. These findings prove that the scale is valid in terms of language, and can be used in its 
Table 1. The demographic characteristics of participating $(n=$ 263).

\begin{tabular}{ccc}
\hline Characteristics & N & \% \\
\hline Participants & & \\
Working nurses & 118 & 44.9 \\
Nursing students & 145 & 55.1 \\
\hline Age & Mean \pm SD & \\
\hline Working nurses & $27.36 \pm 4.54$ \\
Nursing students & $20.17 \pm 1.40$ \\
\hline
\end{tabular}

current form.

\subsection{The Validity of a Scale Similar to Kogan's Attitude towards Old People Scale}

The validity of Kogan's Attitude towards Old People Scale was determined using the similar scale validity method. In order to achieve this, the relationship between the Attitude towards Old People in the Family Inventory and Kogan's Attitude towards Old People Scale correlation was calculated using Pearson Product-Moment Correlation Analysis. The correlation was $r=$ 0.68 , and was found significant at a significance level of $p<0.05$. This result proves that the validity is high according to the similar scale application.

\subsection{Findings Regarding the Test Re-Test Reliability of Kogan's Attitude towards Old People Scale}

In order to determine the test-retest reliability of Kogan's Attitude towards Old People Scale, Kogan's Attitude towards Old People Scale was applied to 145 nursing students and 118 nurses $(n=263)$, and then retest was applied after 30 days. The correlation between the pre-test scores and the post-test scores was calculated with Pearson Product-Moment Correlation Analysis. The correlation was $r=0.78$ at a significance level of $p<$ 0.05 .

\subsection{Findings Regarding the Item-Total Score Reliability of Kogan's Attitude towards Old People Scale}

The item-total score correlation was assessed to determine how the 34 items of Kogan's Attitude towards Old People Scale affect the total score. The correlation was between 0.22 and 0.51 at a significance level of $p<$ 0.05 , excluding items 13 and 14 (Table 2).

\subsection{The Factor Structure of the Items of Kogan's Attitude towards Old People Scale}

The construct validity of Kogan's Attitude towards Old People Scale was determined using factor analysis; factor loads for the 32-item scale varied between .30 and .65 (Table 2). This study was based on a factor load of 0.30 ; items $7,8,19,20,21$, and 22 were eliminated as they were below .30 , and factor analysis was re-applied to the remaining items. After factor analysis, the scale's Kaiser-Meyer Olkin (KMO) coefficient was 0.760 and the result of the Barlett's test determined the significance level as $x^{2}=450.089, p=0.000$. In conclusion of factor analysis, the remaining 26 items gathered under one factor, and only one factor that had an eigen value above 1 and described $28 \%$ of the total variance was found.

\subsection{Findings Regarding the Cronbach Alpha Reliability of Kogan's Attitude towards Old People Scale}

Cronbach's Alpha Coefficient, an indicator of the internal consistency and homogeneity of the items comprising Kogan's Attitude towards Old People Scale, was calculated and found to be 0.81 (Table 3 ).

\subsection{Findings Regarding the Two Split Half Reliability of Kogan's Attitude towards Old People Scale}

The scale was split in two half for the internal consistency reliability coefficient of Kogan's Attitude towards Old People Scale; consistency values for both halves were analysed. Results of the analysis showed that two split-half reliability values relating to the internal consistency of Kogan's Attitude towards Old People Scale was high according to 26 items.

\subsection{The Distinctiveness of Kogan's Attitude towards Old People Scale}

The total scores obtained from Kogan's Attitude towards Old People Scale, after distinctiveness validity analysis, went from low to high. After listing was complete, $27 \%$ of the lower group, and $27 \%$ of the upper group was taken. The $t$-test was used to identify whether or not every item in the scale illustrated distinctiveness between the two groups. The $t$-values relating to every item and total score were found significant at a significance level of $p<0.05$.

\subsection{The Score Mean for Kogan's Attitude towards Old People Scale}

Kogan's Attitude towards Old People Scale was com- 
Table 2. Principal components analysis followed by varimax rotation factor loadings and item-total correlations of the scale and the mean items of the scale $(n=263)$.

\begin{tabular}{|c|c|c|c|c|}
\hline Items of The Scale & $\begin{array}{l}\text { Item-total } \\
\text { correlations }\end{array}$ & $\begin{array}{l}\text { Factor } \\
\text { loading }\end{array}$ & $\mathbf{X} \pm$ & SD \\
\hline $\begin{array}{l}\text { 1) It would probably be better if most old people lived in residential units with people their } \\
\text { own age. }\end{array}$ & $0.342 * *$ & 0.422 & 4.34 & 1.53 \\
\hline 2) It would probably be better if most people lived in residential units with younger people. & $0.466^{* *}$ & 0.520 & 3.96 & 1.38 \\
\hline 3) There is something different about most people; it's hard to find out what makes them tick. & $0.451^{* *}$ & 0.588 & 2.85 & 1.31 \\
\hline $\begin{array}{l}\text { 4) Most old people are really no different from anybody else; they're as easy to understand as } \\
\text { younger people. }\end{array}$ & $0.355^{* *}$ & 0.300 & 3.33 & 1.43 \\
\hline 5) Most old people get set in their ways and are unable to change. & $0.387^{* *}$ & 0.466 & 3.39 & 1.43 \\
\hline 6) Most old people are capable of new adjustments when the situation demands it. & $0.559^{* *}$ & 0.647 & 3.49 & 1.28 \\
\hline 7) Most old people tend to let their homes become shabby and unattractive. & $0.420^{* *}$ & 0.454 & 4.30 & 1.26 \\
\hline 8) Most old people can generally be counted on to maintain a clean, attractive home. & $0.472 * *$ & 0.600 & 3.66 & 1.32 \\
\hline 9) It is foolish to claim that wisdom comes with age. & $0.322 * *$ & 0.300 & 3.90 & 1.36 \\
\hline 10) People grown wiser with the coming of old age. & $0.393^{* *}$ & 0.390 & 3.66 & 1.27 \\
\hline 11) Most old people make one feel ill at ease. & $0.393^{* *}$ & 0.527 & 4.38 & 1.20 \\
\hline 12) Most old people are very relaxing to be with. & $0.469^{* *}$ & 0.624 & 4.29 & 1.17 \\
\hline 13) Most old people bore others by their insistence on talking "about the good old days". & $0.502^{* *}$ & 0.488 & 4.11 & 1.26 \\
\hline $\begin{array}{l}\text { 14) One of the most interesting and entertaining qualities of most old people is their accounts } \\
\text { of their past experiences. }\end{array}$ & $0.254 * *$ & 0.417 & 4.41 & 1.22 \\
\hline $\begin{array}{l}\text { 15) In order to maintain a nice residential neighborhood, it would be best if too many old } \\
\text { people did not live in it. }\end{array}$ & $0.309 * *$ & 0.364 & 4.68 & 1.18 \\
\hline $\begin{array}{l}\text { 16) You can count on finding a nice residential neighborhood when there is a sizeable number } \\
\text { of old people living in it. }\end{array}$ & $0.556^{* *}$ & 0.646 & 3.39 & 1.35 \\
\hline 17) There are a few exceptions, but in general most old people are pretty much alike. & $0.254^{* *}$ & 0.348 & 3.35 & 1.27 \\
\hline 18) It is evident that most old people are very different from one another. & $0.271^{* *}$ & 0.427 & 4.27 & 1.12 \\
\hline $\begin{array}{l}\text { 19) Most old people should be more concerned with their personal appearance; they're too } \\
\text { untitdy. }\end{array}$ & $0.461 * *$ & 0.513 & 4.46 & 1.25 \\
\hline 20) Most old people seem quite clean and neat in their personal appearance. & $0.508^{* *}$ & 0.580 & 3.99 & 1.16 \\
\hline 21) Most old people are irritable, grouchy, and unpleasant. & $0.483^{* *}$ & 0.648 & 3.66 & 1.29 \\
\hline 22) Most old people are cheerful, agreeable, and good humored. & $0.503^{* *}$ & 0.597 & 3.99 & 1.13 \\
\hline 23) Most old people are constantly complaining about the behavior of the younger generation. & $0.425^{* *}$ & 0.551 & 3.95 & 1.25 \\
\hline 24) One seldom hears old people complaining about the behavior of the younger generation. & $0.450^{* *}$ & 0.498 & 3.01 & 1.22 \\
\hline 25) Most old people make excessive demands for love and reassurance than anyone else. & $0.323 * *$ & 0.394 & 3.34 & 1.32 \\
\hline 26) Most old people need no more love and reassurance than anyone else. & $0.422^{* *}$ & 0.475 & 2.48 & 1.48 \\
\hline
\end{tabular}
$* * p<0.01$.

Table 3. Minimum, maximum Scores, scale mean, standard deviation and Cronbach's alpha $(n=263)$.

\begin{tabular}{cccccc}
\hline Total Items & Minimum & Maximum & Mean & SD & $\boldsymbol{\alpha}$ \\
\hline 26 & 50 & 130 & 97.76 & 11.18 & 0.81 \\
\hline
\end{tabular}


prised of 26 items in total and the mean score was $97.76 \pm$ 11.18. The highest score obtainable was 156 , and the lowest score obtainable was 26 (Table 3). The score mean obtained from Kogan's Attitude towards Old People Scale was $83.51 \pm 9.46$ for student nurses participating in the study, and $98.08 \pm 13.13$ for the nurses working at the clinic (Table 4, $p<0.001$ ).

\section{DISCUSSION}

This section analyses the findings related to the validity, reliability, and factor structure of the adapted Turkish version of Kogan's Attitude towards Old People Scale. The test-retest method was used to assess the time invariance of the scale with language validity. The test-retest reliability indicates that results will always be consistent and time invariant, regardless of the application method of the measuring device [13-17]. The correlation between the pre-test scores and the post-test scores was calculated using Pearson Product-Moment Correlation analysis. The correlation was $r=0.78$ at a significance level of $p<0.05$. This result proves that the level of reliability and time invariance of the scale according to test-retest method was high.

Item-total score correlation was analysed in an effort to determine the effect the 34 items of Kogan's Attitude towards Old People Scale has on the total score. The correlation coefficients were between 0.22 and 0.51 at a significance level of $p<0.05$, excluding items 13 and 14 . Literature states that an item-total score correlation above 0.20 and an adequate level of correlation and importance deems the item as good; the level of effectiveness of the item increases together with the increase in correlation [14-16]. The two items with a correlation below 0.20 were eliminated from the scale, leaving the scale with 32 items.

Factor analysis was used to assess the construct validity of Kogan's Attitude towards Old People Scale. "Principle Component Analysis (basic components)" method was used to determine the factor load distribution of the scale's 32 items. Factor analysis was conducted in accordance with Varimax rotation [13,18-20]. When assessed, the factor loads of the scale changed between 0.300 and 0.648 . The minimum factor load/factor coefficient to describe the relationship between item and factor was 30. This study was based on a factor load of 0.30; items $7,8,19,20,21$, and 22 (a total of six items) were eliminated as they were below 0.30 and factor analysis was re-applied to the remaining items. After factor analysis, the scale's Kaiser-Meyer Olkin (KMO) coefficient was 0.760 and the result of the Barlett's test determined the significance level as $x^{2}=450.089, p=0.000$. The fact that the scale's KMO measure was between 70
Table 4. The comparison between attitudes towards older people portrayed by nurses and student nurses $(n=263)$.

\begin{tabular}{ccc}
\hline Participants & Mean \pm SD & $\boldsymbol{t}$ and $\boldsymbol{p}$ \\
\hline Working nurses & $98.08 \pm 13.13$ & $t=10.44$ \\
Nursing students & $83.51 \pm 9.46$ & $p=0.000$ \\
\hline
\end{tabular}

and 79 indicated that the sample group was adequate for analysis. The fact that the Barlett's test was significant indicated that the items of the scale were suitable to conduct factor analyses $[18,20]$.

Cronbach's Alpha Coefficient, an indicator of the internal consistency and homogeneity of the items comprising Kogan's Attitude towards Old People Scale, was calculated and found to be 0.81. Cronbach's Alpha Coefficient, a known reliability measure, must be used to assess the internal consistency of a likert-type scale. The assumption is that high the alpha coefficient the more consistent the items that establish the scale and the scale consists of items predicting the same characteristic elements. Literature states that if Cronbach's Alpha Coefficient is higher than 0.70 , then the measuring tool is reliable and can be used in studies $[14,18,20]$. This study, aimed to determine the validity and reliability of Kogan's Attitude towards Old People Scale (KATOPS), applied the scale to two different groups, and split the scale in half (positive and negative). Psychology students $(n=482)$ established the first group; Cronbach's Alpha Coefficient was 0.77 for the positive scale, and 0.76 for the negative scale. Staff at a geriatrics centre $(n=$ 204) established the second group; Cronbach's Alpha Coefficient was 0.73 for the positive scale, and 0.83 for the negative scale [12]. Schoen assess the scale in two parts (positive and negative); Cronbach's Alpha Coefficient was 0.82 for the positive scale, and 0.86 for the negative scale [21]. Gallagher et al. assessed Kogan's Attitude towards Old People Scale as positive and negative; they indicated that Cronbach's Alpha Coefficient changed between 0.73 and 0.75 [22]. Hilt studied the scale as a whole and found Cronbach's Alpha Coefficient as 0.81 [23]. In line with these results, the internal consistency and homogeneity of the items in the Turkish version of Kogan's Attitude towards Old People Scale are adequate. The Cronbach's Alpha Reliability Coefficient of this study complies with results stated in literature.

The scale was split in half to determine the internal consistency coefficient of Kogan's Attitude towards Old People Scale. The two split half reliability relating to the internal consistency of Kogan's Attitude towards Old People Scale was high as per 26 items. This indicates that the internal consistency reliability of Kogan's Atti- 
tude towards Old People Scale is high.

The total scores obtained from Kogan's Attitude towards Old People Scale, after distinctiveness validity analysis, went from low to high. After listing was complete, $27 \%$ of the lower group, and $27 \%$ of the upper group was taken. The $t$-test was used to identify whether or not every item in the scale illustrated distinctiveness between the two groups. The $t$-values relating to every item and total score gained significance at a significance level of $p<0.05$. This helps to distinguish high and low levels of attitude towards older people depending on the total score and the individual scores of the 26 items of Kogan's Attitude towards Old People Scale.

Kogan's Attitude towards Old People Scale was comprised of 26 items and the mean score was $97.76 \pm 11.18$. This indicates that those participating in the study have a positive attitude towards older people. The attitude of working nurses towards older people was more positive in comparison to the attitude of student nurses. In another study, first-year nurses had more negatives thoughts about older people in comparison to working nurses [24]. The many studies conducted on the subject indicate that nurses working in clinics have a more positive attitude towards older people [9-11]. The results of this study support those stated in literature.

That the reliability and validity of Kogan's Attitude towards Old People Scale was made on only nurses is the limitation of study.

\section{CONCLUSIONS}

In conclusion of this methodological study, we determined that Kogan's Attitude towards Old People Scale had one factor, and its Cronbach Alpha Coefficient was 0.81 . The results of statistical analysis proved that the scale was valid and reliable, and could be used on Turkish society. The Turkish version of Kogan's Attitude towards Old People Scale, tested for validity and reliability, comprised of 26 items and its mean score was 97.76. Working nurses displayed a more positive attitude towards older people in comparison to student nurses. It is suggested that broader groups are used to represent various socio-economic levels in assess the invariance of Kogan's Attitude towards Old People Scale in future studies.

\section{REFERENCES}

[1] Population Reference Bureau, World Population Data Sheet (2011).

http://www.prb.org/pdf10/10wpds eng.pdf

[2] Turkish Statistical Institute (2011) The Database of an address-based population registry system; population according to age group and gender. http://tuikapp.tuik.gov.tr/adnksdagitapp/adnks.zul.pdf
[3] Hacettepe University Institute of Population Studies (2009) A Turkish Population and Health Study 2008, Hacettepe University Institute of Population Studies, Ministry of Health Maternal and Infant Health and Family Planning Directorate, Prime Ministry State Planning Secretariat, and TÜBITAK, Ankara.

[4] Akın, B., Seviğ, Ü. and Karataş, N. (2001) Gerontology nursing training in Turkey. A study to develop a certificate-based program. Cumhuriyet University HYO Journal, 5, 33-39.

[5] Burns, R. and Nickols, L.O. (2000) Interdisiplinary geriatric primary care evaluation and management: Two-year outcomes. Journal of the American Geriatrics Society, 48, 8-13.

[6] Caplan, G.A., Williams, A.J. and Abraham, K. (2004) A Randomized control trial of comprehensive geriatric assesment and multidisiplinary intervention after discharge of elderly from the emergency department. Journal of the American Geriatrics Society, 52, 1417-1423. doi:10.1111/j.1532-5415.2004.52401.x

[7] Akdemir, N., Çınar, F.I. and Görgülü, Ü. (2007) Perceiving old age and geriatric discrimination. Turkish Journal of Geriatrics, 10, 215-222.

[8] Öz, F. (2002) The last stage of life, reviewing old age from a psychosocial point of view. Crisis Journal, 10, 17-28.

[9] Brower, T. (1985) Do nurses stereotype the aged? Journal of Gerontological Nursing, 11, 17-28.

[10] Lookinland, S., Linton, C.P. and Lavender, C. (2002) African-American nurses attitudes toward older persons. The Journal of National Black Nurses Association, 13, 6-14.

[11] Mellor, P., Chew, D. and Greenhill, J. (2007) Nurses attitudes toward elderly people and knowledge of gerontic care in a multipurpose health service. Australian Journal of Advanced Nursing, 24, 37-41.

[12] Kogan, N. (1961) Attitudes toward old people: The development of a scale and an examination of correlations Journal of Abnormal and Social Psychology, 62, 44-54. doi: $10.1037 / \mathrm{h} 0048053$

[13] Tezbaşaran, A. (1996) The guide to developing Likerttype scales. The Association of Turkish Psychologists Publications, Özyurt Matbaas1, Ankara, 45-51.

[14] Özgüven, I.E. (1998) Psychological tests. Nobel Yayınc1lik, Ankara, 83-108

[15] Büyüköztürk, Ş. (2006) The data analysis handbook for social sciences. Pegem Yayıncılık, Ankara.

[16] Gözüm, S. and Aksayan, S. (2002) Guide II for inter-culture scale adaptations: Pyschometric characteristics and intercultural comparisons. Nursing Research and Development Magazine, 4, 9-20.

[17] Erefe, İ. (2002). Nursing study principles, procedures, and methods. Odak Ofset, İstanbul, 172-173.

[18] Akgül, A. (2003) Statistical Analysis Techniques used in Medical Studies. 2nd Edition, Emek Ofset Ltd. Şti., Ankara.

[19] Aksakoğlu, G. (2001) Study Techniques in health, and analysis methods. Dokuz Eylül University Rektörlük Matbaası, İzmir.

[20] Tavşancıl, E. (2002) Measuring attitudes and data analysis using SPSS. Nobel Yayın Dağıtım, Ankara.

[21] Schoen, D. (1993) Nursing students attitudes after an 
experience with independent elderly. Gerontology \& Geriatrics Education, 14, 47-55.

[22] Gallagher, S., Bennett, K.M. and Halford, J.C.G. (2006) A. Comparison of acute and long term health care personel's attitudes toward older adults. International Journal of Nursing Practice, 12, 273-279.

doi:10.1111/j.1440-172X.2006.00582.x
[23] Hilt, M. (1997) Television news and the elderly persons; Broadcast managers' attitudes toward older adults. New York, Garland.

[24] Söderhamn, O., Lindencrona, C. and Gustavsson, S.M. (2001) Attitudes toward older people among nursing students and registered nurses in Sweden. Nurse Education Today, 21, 225-229. 